\title{
Implication of PI3K-dependent HSP27 and p53 expression in mild heat shock-triggered switch of metabolic stress-induced necrosis to apoptosis in A549 cells
}

\author{
SUNG-CHUL LIM ${ }^{1,2}$, HONG-QUAN DUONG ${ }^{1}$, JEONG EUN CHOI ${ }^{1}$, \\ KESHAB RAJ PARAJULI ${ }^{1}$, HO SUNG KANG ${ }^{3}$ and SONG IY HAN ${ }^{1}$ \\ ${ }^{1}$ Research Center for Resistant Cells, ${ }^{2}$ Department of Pathology, College of Medicine, Chosun University, Gwangju 501-759; \\ ${ }^{3}$ Department of Molecular Biology, College of Natural Sciences, Pusan National University, Pusan 609-735, Korea
}

Received September 22, 2009; Accepted November 2, 2009

DOI: 10.3892/ijo_00000511

\begin{abstract}
Previously, we showed that mild heat shock modulates patterns of cell death in response to glucose deprivation (GD), a common characteristic of the tumor microenvironment, by switching necrosis to apoptosis through ERK-dependent suppression of reactive oxygen species production in A549 cells. In the present study, we further examined the molecular mechanism underlying mild heat shock-induced necrosisto-apoptosis switch. We examined the possible implication of p53 and heat shock proteins (HSPs) in the mechanism. Inhibition of p53 by pifithrin- $\alpha$ or p53 siRNA markedly suppressed apoptosis induced by heat shock/GD. On the other hand, silencing of HSP27, but not of HSP70, reversed heat shock/GD-induced apoptosis to necrosis, and HSP27 overexpression suppressed GD-induced necrosis. We further demonstrate that mild heat shock activated AKT and ERK1/2 through phosphorylation. Prevention of PI3K by LY294002 blocked heat shock/GD-induced apoptosis without reversing the cell death mode to necrosis, while inhibition of MEK1/2 by U0126 reversed heat shock/GD-induced apoptosis to necrosis, indicating a different role(s) of PI3K and ERK1/2 in heat shock/GD-induced cell death mode determination. We also found that mild heat shock increased HSP27 and p53 protein levels dependent on PI3K and suppressed the GD-induced increase in RIPA-insoluble HSP27 and p53 protein levels dependent on PI3K and ERK1/2. In conclusion, these results indicate that PI3K-dependent HSP27 and p53 induction and PI3K- and ERK1/2-dependent inhibition of the GD-induced increase in RIPA-insoluble HSP27 and p53 protein levels by heat play a key role(s) in heat shock-mediated switch of GD-induced necrosis to apoptosis.
\end{abstract}

Correspondence to: Dr Song Iy Han, Research Center for Resistant Cells, Chosun University, Gwangju 501-759, Korea

E-mail: sihan@chosun.ac.kr

Key words: p53, heat shock, metabolic stress, necrosis, apoptosis

\section{Introduction}

Under extreme stress, cells die by either apoptosis or necrosis. During necrosis, the cell membrane is ruptured, and the cytosolic constituent including high mobility group box protein 1 (HMGB1) is released into the extracellular spaces, causing strong inflammatory responses $(1,2)$. HMGB1 is a major non-histone chromosomal protein present in nucleus, but it acts as a proinflammatory cytokine when it localizes in extracellular space $(3,4)$. In addition, necrosis has been shown to promote tumor growth and angiogenesis through HMGB1. In contrast, apoptosis is a programmed cell death and is regulated by a variety of cellular signalling pathways. Apoptosis is a tumor suppressive form of cell death, because the cell content remains packed in the apoptotic bodies that are removed by macrophages, thus inflammation is limited. The tumor suppressor p53 is a key protein implicated in apoptosis in response to a variety of stresses including heat shock and genotoxic chemicals. The apoptotic activity of p53 is thought to be mediated by its role as a transcription factor modulating the expression of several genes, including PUMA, BAX, Noxa, p21, and GADD45 as well as through non-transcriptional regulation (5-7). Under normal conditions, cellular p53 is maintained in a very low level, owing to its association with murine double minute 2 (MDM2), a negative regulatory binding protein, and proteasomal degradation $(8,9)$. DNA damaging signal by ionizing radiation or genotoxic stresses triggers dissociation of MDM2 from p53, which results from p53 phosphorylation by the PI3K-related kinases. p53 is phosphorylated by the PI3K-related kinases including ATM and ATR or other kinases, leading to p53 activation $(10,11)$. PI3K is well known as a proliferation- and survivalrelated signaling regulator and the PI3K pathway is frequently deregulated in human cancer. Since activating mutations and gene amplifications of PI3K are often found in various human malignancies, it is considered as a potential oncogene $(12,13)$. Interestingly, p53 induction by cisplatin is blocked by the PI3K inhibitor LY294002, implicating the PI3K pathway as the critical mediator in p53 activation (14).

In solid tumors, necrosis is commonly found in the core region by depletion of glucose and oxygen and is implicated in tumor progression and aggressiveness. Previously, we have 
found that mild heat shock could switch glucose deprivation (GD)-induced necrosis to apoptosis through extracellular regulated kinase (ERK)-dependent inhibition of GD-induced reactive oxygen species production in A549 cells, suggesting that the necrosis-to-apoptosis switching effects of mild heat shock may contribute to the tumor-suppressive activities of hyperthermia (15). In general, severe heat shock acts as proteotoxic stress by causing protein denaturation, and exerting a variety of anti-proliferative and apoptotic effects in mammalian cells (16). However, mild heat shock has been shown to positively regulate cell survival and proliferation. For example, mild heat shock facilitates activation of resting lymphocytes for proliferation and effecter formation (17), stimulates bone marrow stromal cell proliferation (18), and induces the synthesis of cyclin D1, which plays a critical role(s) in the G1 progression of the cell cycle through multiple Ras signal pathways involving Rac1/NADPH oxidase, ERK, and PI3K (19). Furthermore, mild heat shock-induced heat shock protein (HSP) expression is regulated by a small GTPase Rac1, while harsh heat shock-induced HSP expression is not (20). HSPs are a family of highly conserved proteins found in all prokaryotes and eukaryotes (21). HSPs assist appropriate folding, assembly of newly synthesized polypeptides, and help intracellular trafficking of proteins in normal cells (22), and protect cells against stressful stimuli $(23,24)$, and participate in the modulation of several apoptotic processes (25). They are generally found at elevated levels in various tumors including breast, prostate, colon and liver carcinoma, and their expression often correlates with increased cell proliferation and poor response to chemotherapy $(26,27)$, thus, inhibition of HSPs has been suggested to be a potential target of anti-cancer therapy (28). Besides the anti-apoptotic role of HSPs, however, recent studies have indicated that HSPs are also involved in tumor immunogenicity and antigen presentation in ovarian carcinoma, melanoma, and osteosarcoma $(29,30)$.

In the present study, we examined the role of HSPs and p53 in mild heat shock-potentiated cell death mode regulation and evaluated the signal pathways responsible for the alteration in HSP and p53 levels during GD-induced necrosis and heat shock-potentiated apoptotic switches.

\section{Materials and methods}

Cell culture and drug treatment. A549 cells were maintained in RPMI-1640 medium (Invitrogen) containing 10\% FBS and $1 \% \mathrm{PS}$ at $37^{\circ} \mathrm{C}$ in $5 \% \mathrm{CO}_{2}$. For GD treatment, cells were gently rinsed with PBS and incubated in GD medium (glucosefree RPMI-1640 medium (Invitrogen) containing 10\% dialyzed FBS and 1\% PS). For heat shock treatment, A549 cells were incubated at $41^{\circ} \mathrm{C}$ for $2.5 \mathrm{~h}$ and then allowed to recover at $37^{\circ} \mathrm{C}$. To examine the effects of inhibitors, cells were pretreated with chemicals [U0126 $(20 \mu \mathrm{M})$, PD98059 $(30 \mu \mathrm{M})$, pifithrin- $\alpha$ (PFT- $\alpha)(30 \mu \mathrm{M})$, or LY294002 $(20 \mu \mathrm{M})]$ for $1 \mathrm{~h}$, then exposed to heat shock or GD treatment in the presence of the inhibitors. Unless specified, drugs were purchased from Calbiochem (San Diego, CA).

RNA interference. siRNA of p53 5'-CACUACAACUACAU GUGUA-3' (S) 5'-UACACAUGUAGUUGUAGUG (dTdT)-
5' (AS), siRNA of HSP27 5'-AAGCUGCAAAAUCCG AUGAGAC-3' (S) 5'-GUCUCAUCGGAUUUUGCAG CUU-3' (AS), siRNA of HSP70 5'-CUGUGUUUGCAAUG UUGAA (dTdT)-3' (S) 5'-UUCAACAUUGCAAACACAG (dTdT)-3' (AS), and scrambled RNA sequence 5'-CCUACG CCACCAAUUUCGU (dTdT)-3' (S) 5'-ACGAAAUUG GUGGCGUAGG (dTdT)-3' (AS) were designed and synthesized by Bioneer (Daejeon, Korea). Cells $\left(10^{6}\right)$ were transfected with $5 \mu \mathrm{g}$ siRNA using Amaxa transfection kit. Then cells were grown for $48 \mathrm{~h}$ prior to GD treatment.

EGFP-HSP27 vector construction and transfection. The 617-bp human HSP27 coding sequence amplified with primer pairs (HSP27-sense: AGCTTCGAATTCCGGCGG ATGACCGAGCGCCGCGTCCCCTTC and HSP27-antisense: CCGGTGGATCCCTTACTTGGCGGCAGTCT CATC) by RT-PCR reaction was excised with EcoRI and BamHI. The fragment was purified and ligated into similarly cut pEGFP-C2 (Clontech, Palo Alto, CA), a mammalian expression vector containing the CMV promoter and allowing in frame fusion between EGFP and the human HSP27 gene. The fusion protein ( $\mathrm{pEGFP}-\mathrm{C}_{2}-\mathrm{HSP} 27$ ) was produced by joining the carboxy terminus of the GFP with the amino terminus of the HSP27. This vector pEGFP- $\mathrm{C}_{2}-\mathrm{HSP} 27$ and control vector pEGFP- $\mathrm{C}_{2}$ was then tranfected separately into A549 cells using Polyplus transfection reagent. Clones containing the pEGFP- $\mathrm{C}_{2}$ and the pEGFP-C $\mathrm{C}_{2}-\mathrm{HSP} 27$ were selected and maintained in media containing G418.

Hoechst 33342 (HO)/propidium iodide (PI) staining assay. Cells were incubated either with $1 \mu \mathrm{g} / \mathrm{ml} \mathrm{HO}$ and $5 \mu \mathrm{g} / \mathrm{ml} \mathrm{PI}$ at $37^{\circ} \mathrm{C}, 5 \% \mathrm{CO}_{2}$ for $15 \mathrm{~min}$ and then both floating and attached cells were collected. The pooled cell pellets were immediately fixed in $3.7 \%$ formaldehyde, washed with PBS, resuspended, and a fraction of the suspension was centrifuged in a cytospinner (Hanil). The slides were rinsed, air dried, mounted and examined by fluorescence microscopy at 340/425 nm (HO), and 580/630 nm (PI) (D5000 Leica, Germany). A total of 500 cells from several random fields were counted, and the number of apoptotic and necrotic cells were espressed as a percentage of the total number of cells scored.

Lactate dehydrogenase $(\mathrm{LDH})$ release assay. $\mathrm{LDH}$ release was quantified using an LDH cytotoxicity assay kit II (BioVision, Mountain View, CA) according to the manufacturer's protocol. Briefly, cells cultured in 96-well plates were treated with drugs for $18 \mathrm{~h}$. The plates were centrifuged at $600 \mathrm{~g}$ for $10 \mathrm{~min}$, and the cell-free supernatant was transferred to a new 96-well plate, mixed with LDH Reaction Mix, and measured the absorbance at $450 \mathrm{~nm}$. The percentage of specific LDH release was calculated by the following formula: $\%$ cytotoxicity = [(experimental LDH release)-(spontaneous LDH release by effector and target)/(maximum LDH release) - (spontaneous LDH release)] x 100. The spontaneous release of LDH activity from control cells was $<2 \%$ of the maximal release of $\mathrm{LDH}$ activity, which was determined from the complete lysis.

Immunoblot analysis. Electrophoretically separated proteins were transferred to an NC membrane, blocked in 5\% skimmilk/TBST, and incubated with primary antibodies to PARP 
A

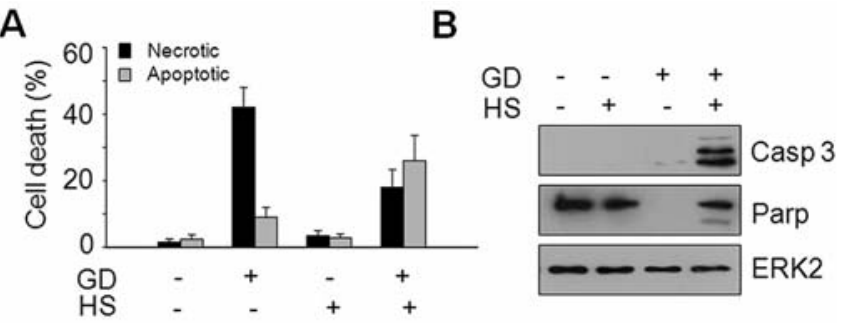

Figure 1. Mild heat shock switches GD-induced necrosis to apoptosis. A549 cells were incubated at 37 or $41^{\circ} \mathrm{C}$ for $2.5 \mathrm{~h}$ and exposed to GD medium at $37^{\circ} \mathrm{C}$ for $18 \mathrm{~h}$. Then cells were stained with $\mathrm{HO} / \mathrm{PI}$ and apoptotic and necrotic cells were scored under a fluorescence microscope, as described in Materials and methods (A), or active-caspase 3 and PARP were detected by Western blotting (B). ERK2, loading control.

(BD Biosciences), active caspase-3, p-Akt(ser473), Akt (Cell Signaling), p53, p-ERK1/2, ERK2, ß-actin (Santa Cruz), HSP27, HSP70 or HSP90 (Stress Gen). Then, the membranes were incubated with HRP-conjugated secondary antibody and visualized with Super Signal chemiluminescence kit (Pierce Biotechnology), and finally the signals were acquired by image analyzer (Image station $4000 \mathrm{MN}$, Kodak).

\section{Results and Discussion}

Heat shock switches glucose depletion-induced necrosis to apoptosis. As demonstrated previously, GD induced mainly necrosis in A549 cells but pre-exposure to mild heat shock $\left(41^{\circ} \mathrm{C} / 2.5 \mathrm{~h}\right)$ significantly converted GD-induced necrosis to apoptosis as determined by HO/PI double staining (Fig. 1A). DNA-binding dyes (HO) stain all nuclei that enable to distinguish nuclear morphology and PI penetrate cells with damaged membranes, thus intact blue nuclei, condensed/ fragmented blue nuclei, condensed/fragmented pink nuclei, and intact pink nuclei were considered viable, early apoptotic, late apoptotic, and necrotic cells, respectively. This was further supported by Western blotting showing caspase 3 activation and PARP cleavages which are general molecular events of apoptosis (Fig. 1B).

p53 is involved in the heat shock/GD-induced apoptosis. The tumor suppressor p53 is a key protein implicated in apoptosis in response to a variety of stresses including heat shock and genotoxic agents. We investigated whether p53 protein is related with the cell death mode determination. To explore the role of p53 protein in heat shock/GD-induced apoptosis, we assessed cell death pattern when p53 is prevented by either PFT- $\alpha$, inhibitor of transcriptional activity, or silencing of p53 using small interference RNA ( Both PFT- $\alpha$ and silencing of p53 significantly decreased heat shock/GD-induced apoptotic body formation, without affecting necrotic cell death (Fig. 2A-C), indicating that p53 is involved in induction of apoptosis but not in heat shock-induced suppression of necrosis. In line with this, caspase 3 cleavage was also decreased by p53 inhibition,
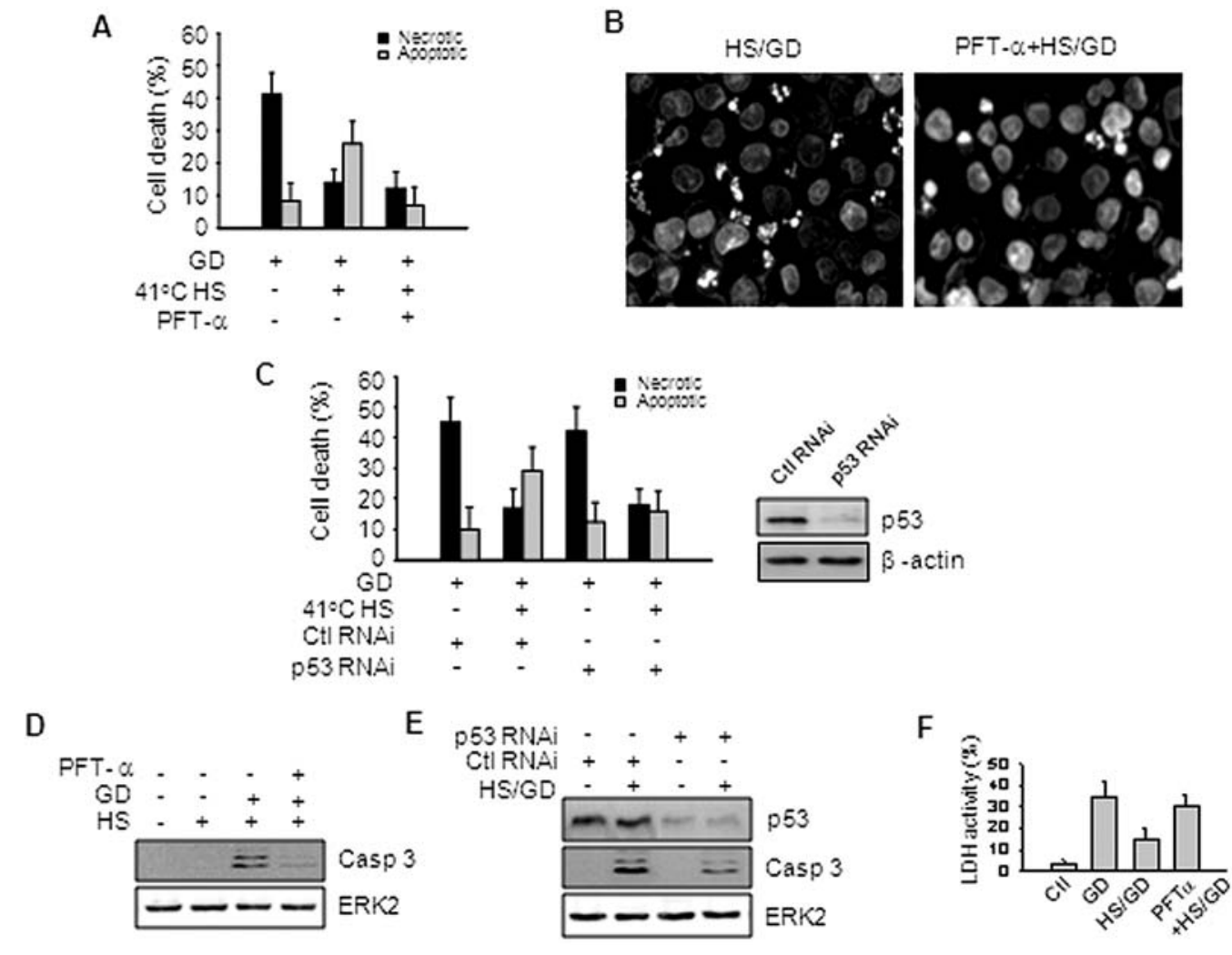

Figure 2. p53 plays critical role in the heat shock/GD-induced apoptosis. (A and B) Cells were exposed to GD or heat shock/GD in the absence or presence of $30 \mu \mathrm{M}$ PFT- $\alpha$, and stained with HO/PI (A). HO stained images are shown in B (x400). (C) Cells were transfected with scrambled RNA (ctl RNAi) or p53 RNAi for $48 \mathrm{~h}$ and subjected to Western blotting to confirm p53 silencing. The cells were incubated at 37 or $41^{\circ} \mathrm{C}$ for $2.5 \mathrm{~h}$ and exposed to GD medium at $37^{\circ} \mathrm{C}$ for $18 \mathrm{~h}$ and then stained with HO/PI. (D and E) A549 cells were either exposed to heat shock/GD in the presence or absence of $30 \mu \mathrm{M}$ PFT- $\alpha$ (D), or transfected with ctl RNAi or p53 RNAi and then treated with heat shock/GD (E) and subjected to Western blotting to detect active caspase 3, p53, and ERK2. (F) Cells were exposed to GD or heat shock/GD in the absence or presence of PFT- $\alpha$ for $18 \mathrm{~h}$, then media were taken and measured for LDH activity. 
A
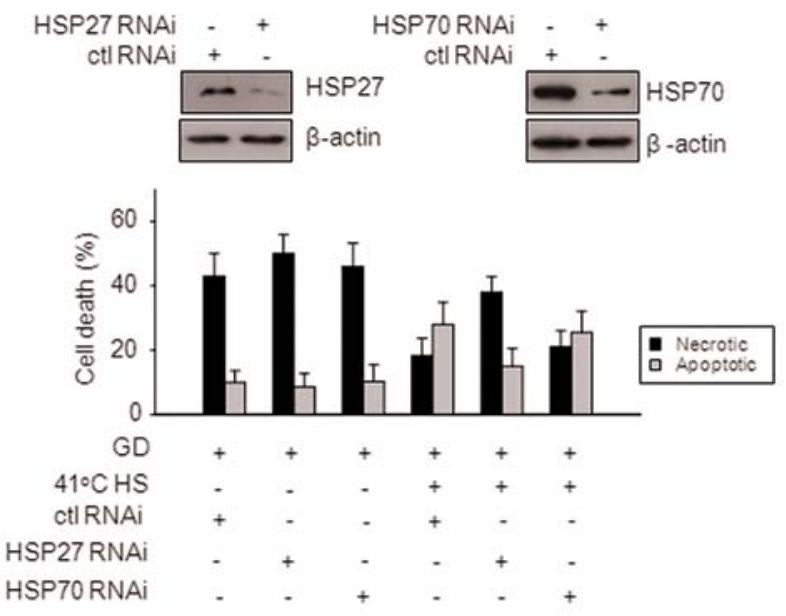

B

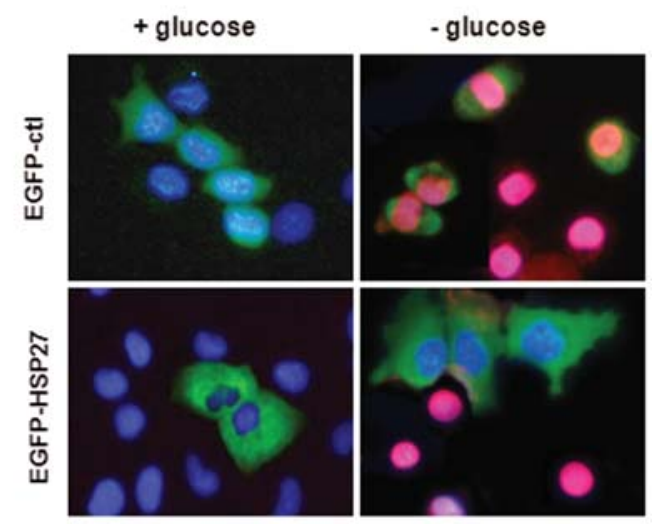

Figure 3. Interference of HSP27, but not HSP70, reversed the activity of mild heat shock to switch GD-induced necrosis to apoptosis. (A) A549 cells were transiently transfected with $5 \mu \mathrm{g} / \mathrm{ml}$ of ctl RNAi, HSP27 RNAi, or HSP70 RNAi. Then the cells were treated with GD or heat shock/GD and stained with HO/PI. Decreased expression of HSP27, and HSP70 were confirmed by Western blotting with anti-HSP27 and anti-HSP70 antibody (left panel). (B) Overexpression of HSP27 protected GD-induced necrosis. Cells stably overexpressing pEGFP-C $\mathrm{C}_{2}$ vector or pEGFP- $\mathrm{C}_{2}$-HSP27 vector were incubated $12 \mathrm{~h}$ in normal growth medium or GD medium, and then incubated with HO/PI for $15 \mathrm{~min}$. The cells were rinsed, filled with fresh medium, and fluorescence images were captured under an inverted fluorescence microscope (x400, Olympus).

whereas LDH release was not increased (Fig. 2D-F). These results suggest that p53 is required for execution of apoptosis in response to heat shock/GD, but insufficient to switch GD-induced necrosis to apoptosis.

HSP27, but not HSP70, prevents GD-induced necrosis. HSPs such as HSP70 and HSP27 play a major role in the protection of cells against stressful stimuli $(23,24)$ and participate in the modulation of several apoptotic processes (25). Thus, we investigated whether HSP27 or HSP70 is linked to the cell death mode determination in heat shock/GD-induced cell death. HSP27 or HSP70 was silenced by transfection of siRNA for each gene and then cell death patterns were determined after GD or heat shock/GD. As shown in Fig. 3A, the heat shock effect that switches GD-induced necrosis to apoptosis was significantly reversed in HSP27 silenced cells, whereas in the cells transfected with HSP70 siRNA, the heat shock effect was not altered with similar pattern to the cells transfected with scrambled siRNA. Thus, HSP27 appeared to play a critical role in the heat shock-induced cell death mode switching effect in GD condition. To further explore whether HSP27 is directly linked to the conversion of GD-induced necrosis to apoptosis, A549 cells constitutively overexpressing HSP27 were established and subjected to GD. Cell death mode was observed at $18 \mathrm{~h}$ after GD for necrosis and at $24 \mathrm{~h}$ after GD for apoptosis by HO/PI staining, since necrotic and apoptotic death maximally occur at the respective timepoints. At $18 \mathrm{~h}$, mostly red nuclei (indicating necrotic cell death) were observed in cells transfected with pEGFP-C ${ }_{2}$, but blue nuclei (indicating viable cells) were detected in pEGFP$\mathrm{C}_{2}$-HSP27 cells, indicating that GD-induced necrosis was suppressed in the cells overexpressing HSP27 (Fig. 3B). However, apoptotic body formation was not detected in pEGFP-C $\alpha$-HSP27 cells until $24 \mathrm{~h}$ after GD (data not shown). Therefore, HSP27 appears to play an important role(s) in the heat shock-mediated necrosis-to-apoptosis switch, but it is not sufficient for switching necrosis to apoptosis.
A

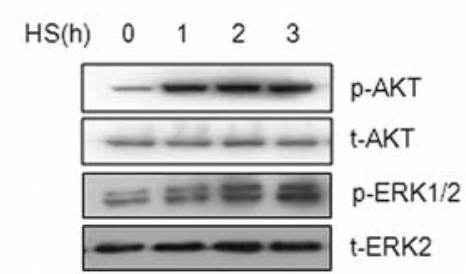

B

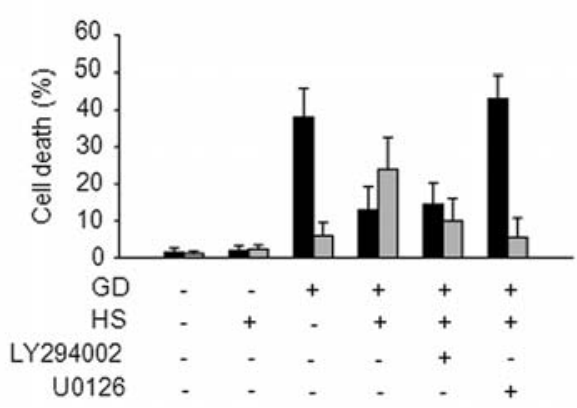

Figure 4. PI3K and ERK pathways are involved in heat shock/GD-induced apoptosis. (A) A549 cells treated with $41^{\circ} \mathrm{C}$ heat shock for 1,2 , and $3 \mathrm{~h}$ were harvested and analyzed by Western blotting for phospho-Akt, Akt, phosphor-ERK1/2, and ERK1/2. (B) A549 cells were pretreated with vehicle, LY294002, or U0126 and then exposed to heat shock/GD and stained by $\mathrm{HO} / \mathrm{PI}$ and apoptotic and necrotic cells were scored under a fluorescence microscope.

Heat shock-activated Akt/PKB and ERK1/2 pathways play a critical role(s) in cell death mode determination in heat shock/GD condition. Since mild heat shock activates multiple Ras signal-dependent PI3K and ERK1/2 pathways, we examined whether these pathways are linked to the cell death mode determination in heat shock/GD. Mild heat shock activated Akt and ERK through phosphorylation in A549 cells (Fig. 4A). The addition of the MEK inhibitor U0126 converted the heat shock/GD-induced apoptosis to necrosis, indicating that ERK1/2 may play a role in mild heat shockmediated prevention of necrosis induced by GD (Fig. 4B). Interestingly, the PI3K inhibitor LY294002 blocked formation 
A

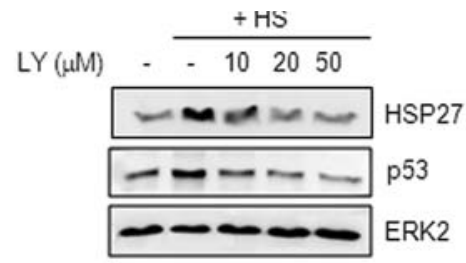

C

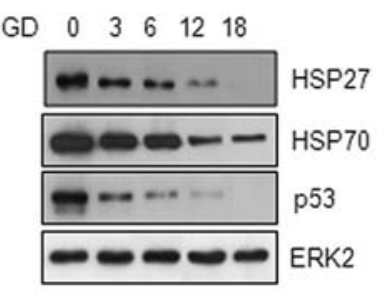

F

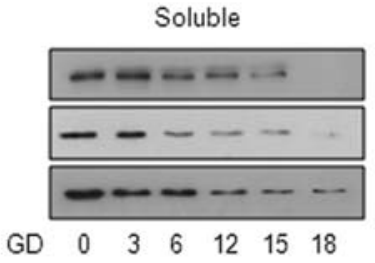

D

HS

B

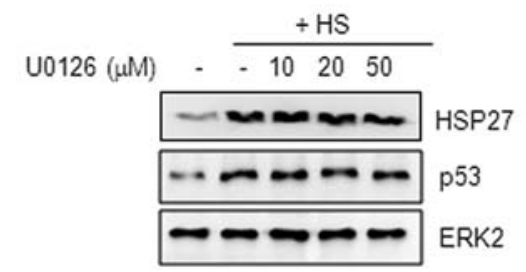

E
H. + +

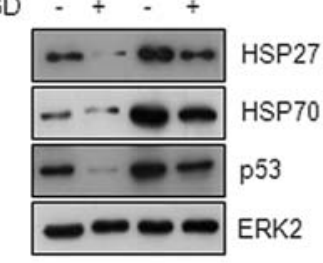

p 53 HSP27
G

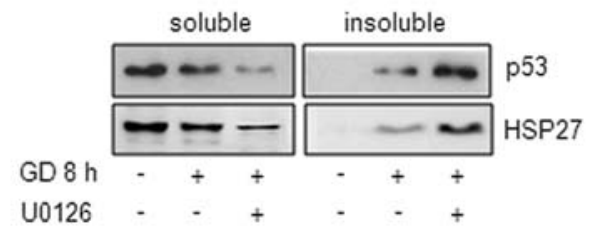

Insoluble

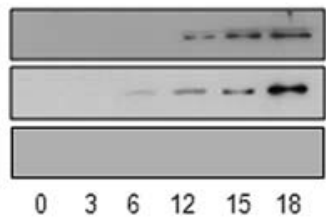

Medium

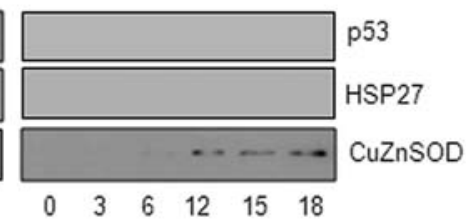

H

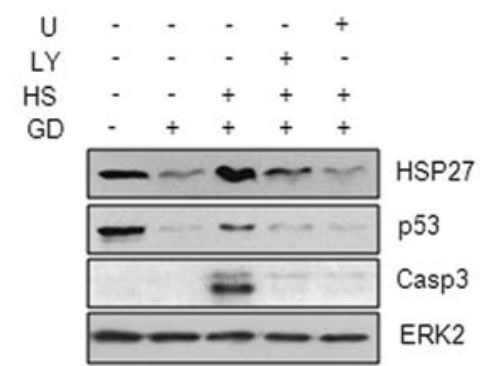

Figure 5. HSP27 and p53 protein levels are regulated by PI3K and ERK pathways. Cellular protein or released protein levels were analyzed by SDS-PAGE and Western blotting after treatment as follows. (A and B) Cells exposed to $41^{\circ} \mathrm{C}$ heat shock for $2.5 \mathrm{~h}$ in the absence or presence of 10 , 20 , or $50 \mu \mathrm{M}$ LY294002 (A), or presence of 10, 20, or $50 \mu \mathrm{M}$ U0126 (B) were further incubated in $37^{\circ} \mathrm{C}$ for $18 \mathrm{~h}$. (C) A549 cells were incubated in GD medium for the indicated times. (D) A549 cells were exposed to $37^{\circ} \mathrm{C}$ or $41^{\circ} \mathrm{C}$ for $2.5 \mathrm{~h}$, and further cultured in normal growth medium (GD) or GD medium (GD $)$ for $18 \mathrm{~h}$. (E) A549 cells were either incubated in GD medium alone or pretreated with $10 \mu \mathrm{M}$ MG132, $10 \mu \mathrm{M}$ lactacystin or $10 \mu \mathrm{M}$ ALLN and exposed to GD medium in the presence of the inhibitors. (F) After incubation in GD medium for the indicated times, cells were collected, lysed in RIPA solution, then soluble and insoluble fractions were divided by centrifugation (12,000 rpm). Equal amount of proteins were taken for soluble protein analysis (Soluble), while insoluble protein aggregates were solubilized in Laemmli's sample buffer and equal volumes of the solution were taken (insoluble). At respective time, medium was also taken and concentrated (medium) and then subjected to Western blotting. (G) Soluble and insoluble proteins were obtained after incubation in the GD medium for $8 \mathrm{~h}$ in the presence or absence of $10 \mu \mathrm{M}$ U0126. (H) A549 cells were exposed to heat shock in the absence or presence of LY294002 or U0126 and then treated with the GD medium for $18 \mathrm{~h}$.

of apoptotic bodies after heat shock/GD, but without increasing PI inclusion, a necrotic feature of cell death (Fig. 4B), indicating that the PI3K-Akt signal cascade exert proapoptotic activities. Although PI3K-Akt pathway is a typical pro-survival pathway, recent studies demonstrated that PI3K pathway is also involved in apoptotic cell death (31-33). We also found that LY294002 could prevent apoptosis by combined treatment of GD and hypoxia, anti-oxidants [NAC (a general antioxidant) or catalase (an $\mathrm{H}_{2} \mathrm{O}_{2}$ scavenger)], or the PKC activator phorbol-12-myristate-13-acetate (unpublished data). In addition, the PI3K pathway is involved in high glucose triggered apoptosis in human umbilical vein endothelial cells and interferon- $\alpha$-induced caspase-dependent apoptosis (33). Thus, the PI3K-Akt signaling may exert a proapoptotic activity in apoptotic cell death that occurs due to altered cellular oxygen or glucose levels or in response to a specific set of apoptotic stimuli, although its exact molecular mechanism remains to be clarified.
Mild heat shock increased HSP27 and p53 protein levels dependent on PI3K and suppressed the GD-induced accumulation of RIPA-insoluble HSP27 and p53 protein dependent on PI3K and ERK1/2. As demonstrated previously, heat shock increased HSP27 and p53 protein levels. The induction was prevented by PI3K inhibitor LY294002, but not by MEK inhibitor U0126 (Fig. 5A and B). Similarly, $\mathrm{PI} 3 \mathrm{~K}$ has been shown to participate in phosphorylation or induction of HSP27 in response to various stimuli, including acidic pH stress-induced HSP27 induction in human esophageal microvascular endothelial cells, vasopressininduced HSP27 phosphorylation in aortic smooth muscle A10 cells, and sphingosine 1-phosphate-stimulated HSP27 induction in osteoblasts (34-36). In addition, PI3K pathway has been demonstrated as the critical mediator in p53 activation in response to cisplatin (14).

In the course of this study, we found that GD decreased RIPA-soluble levels of several proteins including HSP27, 


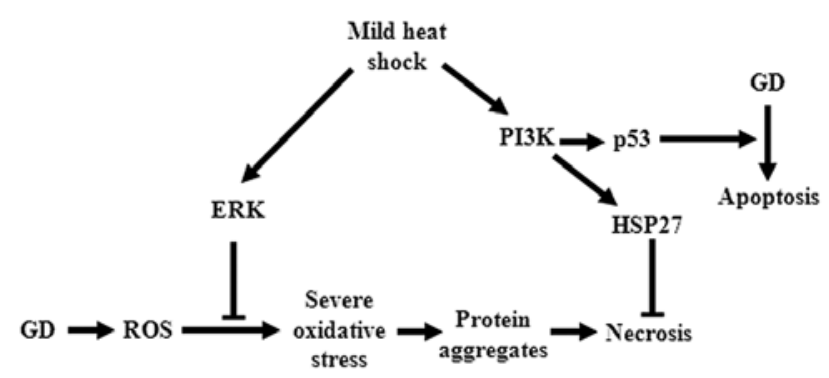

Figure 6. A schematic model for mild heat shock-mediated cell death mode switch.

HSP70, and p53 (Fig. 5C). However, when heat shock was pretreated, the GD-mediated decrease of HSP27, HSP70, and p53 was significantly recovered (Fig. 5D). In general, several damaged cellular proteins are recognized by ubiquitin system and subsequently degraded by proteasome (37) or calpain that plays important roles in the necrotic death of many cells (38). However, reduction of p53 and HSP27 was not changed by the proteasome inhibitors MG132 and lactacystin, or the calpain inhibitor ALLN, indicating that proteasome or calpain may not be responsible for decrease of p53 and HSP27 protein (Fig. 5E). p53 and HSP27 were detected in a RIPA-insoluble fraction after GD, indicating that p53 and HSP27 proteins may form insoluble large aggregates during GD. The RIPAinsoluble aggregates formation increased in a time-dependent manner (Fig. 5F). Upon GD-induced oxidative stress, proteins could be oxidized, tend to aggregate and become cytotoxic. Cell death by polypeptide aggregation has been well studied as a causative factor of various human neurodegenerative disorders. U0126 accelerated aggregate formation of p53 and HSP27, and reversed the heat shock effect that prevents GD-triggered protein aggregation (Fig. 5G and H). We have previously shown that in A549 cells, GD was accompanied by release of cytosolic CuZnSOD into extracellular medium, resulting in strong oxidative stress (39). In this regard, aggregation of p53 and HSP27 appears to be closely associated with incurrence of excessive oxidative stress.

Our results indicate that PI3K-dependent HSP27 and p53 induction and PI3K- and ERK1/2-dependent inhibition of the GD-induced increase in RIPA-insoluble HSP27 and p53 protein levels by heat play a key role(s) in heat shock-mediated switch of the GD-induced necrosis to apoptosis. Heat shockpotentiated conversion of necrosis to apoptosis is likely to require at least 2 separate events; blocking of necrosis and induction of apoptosis.

\section{Acknowledgements}

This research was supported by Basic Science Research Program through the National Research Foundation of Korea (NRF) funded by the Ministry of Education, Science and Technology (KRF-2007-531-C00043).

\section{References}

1. Yang H, Wang H, Czura CJ and Tracey KJ: The cytokine activity of HMGB1. J Leukoc Biol 78: 1-8, 2005.

2. Zong WX and Thompson CB: Necrotic death as a cell fate. Genes Dev 20: 1-15, 2006.
3. Lotze MT and Tracey KJ: High-mobility group box 1 protein (HMGB1): nuclear weapon in the immune arsenal. Nat Rev Immunol 5: 331-342, 2005.

4. Scaffidi P, Misteli T and Bianchi ME: Release of chromatin protein HMGB1 by necrotic cells triggers inflammation. Nature 418: 191-195, 2002.

5. Chen X, Ko LJ, Jayaraman L and Prives C: p53 levels, functional domains, and DNA damage determine the extent of the apoptotic response of tumor cells. Genes Dev 10: 2438-2451, 1996.

6. Manfredi JJ: p53 and apoptosis: it's not just in the nucleus anymore. Mol Cell 11: 552-554, 2003.

7. Sharpless NE and De Pinho RA: p53: good cop/bad cop. Cell 110: 9-12, 2002.

8. Kubbutat MH, Jones SN and Vousden KH: Regulation of p53 stability by Mdm2. Nature 387: 299-303, 1997.

9. Maki CG, Huibregtse JM and Howley PM: In vivo ubiquitination and proteasome-mediated degradation of p53(1). Cancer Res 56: 2649-2654, 1996.

10. Latonen L, Kurki S, Pitkanen K and Laiho M: p53 and MDM2 are regulated by $\mathrm{PI}-3$-kinases on multiple levels under stress induced by UV radiation and proteasome dysfunction. Cell Signal 15: 95-102, 2003.

11. Hurley PJ and Bunz F: ATM and ATR: components of an integrated circuit. Cell Cycle 6: 414-417, 2007.

12. Samuels Y, Wang Z, Bardelli A, Silliman N, Ptak J, Szabo S, Yan H, Gazdar A, Powell SM, Riggins GJ, Willson JK, Markowitz S, Kinzler KW, Vogelstein B and Velculescu VE: High frequency of mutations of the PIK3CA gene in human cancers. Science 304: 554, 2004.

13. Vivanco I and Sawyers CL: The phosphatidylinositol 3-kinase AKT pathway in human cancer. Nat Rev Cancer 2: 489-501, 2002.

14. Bar J, Lukaschuk N, Zalcenstein A, Wilder S, Seger R and Oren M: The PI3K inhibitor LY294002 prevents p53 induction by DNA damage and attenuates chemotherapy-induced apoptosis. Cell Death Differ 12: 1578-1587, 2005.

15. Han SI, Duong HQ, Choi JE, Lee TB, Kim CH, Lee SY, Jeon HM, Shin SH, Lim SC and Kang HS: Hyperthermia switches glucose depletion-induced necrosis to apoptosis in A549 lung adenocarcinoma cells. Int J Oncol 32: 851-860, 2008.

16. Katschinski DM, Boos K, Schindler SG and Fandrey J: Pivotal role of reactive oxygen species as intracellular mediators of hyperthermia-induced apoptosis. J Biol Chem 275: 21094-21098, 2000.

17. Hanson DF: Fever, temperature, and the immune response. Ann NY Acad Sci 813: 453-464, 1997.

18. Shui C and Scutt A: Mild heat shock induces proliferation, alkaline phosphatase activity, and mineralization in human bone marrow stromal cells and Mg-63 cells in vitro. J Bone Miner Res 16: 731-741, 2001.

19. Han SI, Oh SY, Jeon WJ, Kim JM, Lee JH, Chung HY, Choi YH, Yoo MA, Kim HD and Kang HS: Mild heat shock induces cyclin D1 synthesis through multiple Ras signal pathways. FEBS Lett 515: 141-145, 2002.

20. Han SI, Oh SY, Woo SH, Kim KH, Kim JH, Kim HD and Kang HS: Implication of a small GTPase Rac1 in the activation of c-Jun N-terminal kinase and heat shock factor in response to heat shock. J Biol Chem 276: 1889-1895, 2001.

21. Ang D, Liberek K, Skowyra D, Zylicz M and Georgopoulos C: Biological role and regulation of the universally conserved heat shock proteins. J Biol Chem 266: 24233-24236, 1991.

22. Pratt WB: The role of heat shock proteins in regulating the function, folding, and trafficking of the glucocorticoid receptor. J Biol Chem 268: 21455-21458, 1993.

23. Nakamura K, Rokutan K, Marui N, Aoike A and Kawai K: Induction of heat shock proteins and their implication in protection against ethanol-induced damage in cultured guinea pig gastric mucosal cells. Gastroenterology 101: 161-166, 1991.

24. Sciandra JJ and Subjeck JR: Heat shock proteins and protection of proliferation and translation in mammalian cells. Cancer Res 44: 5188-5194, 1984

25. Takayama S, Reed JC and Homma S: Heat-shock proteins as regulators of apoptosis. Oncogene 22: 9041-9047, 2003.

26. Gibbons NB, Watson RW, Coffey RN, Brady HP and Fitzpatrick JM: Heat-shock proteins inhibit induction of prostate cancer cell apoptosis. Prostate 45: 58-65, 2000.

27. Jolly C and Morimoto RI: Role of the heat shock response and molecular chaperones in oncogenesis and cell death. J Natl Cancer Inst 92: 1564-1572, 2000. 
28. Blagosklonny MV: Hsp-90-associated oncoproteins: multiple targets of geldanamycin and its analogs. Leukemia 16: 455-462, 2002.

29. Trieb K, Lang S and Kotz R: Heat-shock protein 72 in human osteosarcoma: T-lymphocyte reactivity and cytotoxicity. Pediatr Hematol Oncol 17: 355-364, 2000.

30. Welch WJ: Mammalian stress response: cell physiology, structure/ function of stress proteins, and implications for medicine and disease. Physiol Rev 72: 1063-1081, 1992.

31. Hamanaka Y, Mukai M, Shimamura M, Kitagawa T, Nishida T, Isohashi F, Ito T, Nishizawa $\mathrm{Y}$, Tatsuta $\mathrm{M}$, Matsuda $\mathrm{H}$ and Inoue M: Suppression of PI3K/mTOR pathway rescues LLC cells from cell death induced by hypoxia. Biochem Biophys Res Commun 330: 318-326, 2005

32. Sheu ML, Ho FM, Yang RS, Chao KF, Lin WW, Lin-Shiau SY and Liu SH: High glucose induces human endothelial cell apoptosis through a phosphoinositide 3-kinase-regulated cyclooxygenase-2 pathway. Arterioscler Thromb Vasc Biol 25: 539-545, 2005

33. Thyrell L, Hjortsberg L, Arulampalam V, Panaretakis T, Uhles S, Dagnell M, Zhivotovsky B, Leibiger I, Grander D and Pokrovskaja K: Interferon alpha-induced apoptosis in tumor cells is mediated through the phosphoinositide 3-kinase/ mammalian target of rapamycin signaling pathway. J Biol Chem 279: 24152-24162, 2004.

34. Rafiee P, Theriot ME, Nelson VM, Heidemann J, Kanaa Y, Horowitz SA, Rogaczewski A, Johnson CP, Ali I, Shaker R and Binion DG: Human esophageal microvascular endothelial cells respond to acidic $\mathrm{pH}$ stress by PI3K/AKT and p38 MAPKregulated induction of Hsp70 and Hsp27. Am J Physiol Cell Physiol 291: C931-C945, 2006.
35. Suga H, Nakajima K, Shu E, Kanno Y, Hirade K, Ishisaki A, Matsuno H, Tanabe K, Takai S, Akamatsu S, Kato K, Oiso Y and Kozawa O: Possible involvement of phosphatidylinositol 3kinase/Akt signal pathway in vasopressin-induced HSP27 phosphorylation in aortic smooth muscle A10 cells. Arch Biochem Biophys 438: 137-145, 2005

36. Takai S, Tokuda H, Matsushima-Nishiwaki R, Hanai Y, Kato K and Kozawa O: Phosphatidylinositol 3-kinase/Akt plays a role in sphingosine 1-phosphate-stimulated HSP27 induction in osteoblasts. J Cell Biochem 98: 1249-1256, 2006.

37. Poppek D and Grune T: Proteasomal defense of oxidative protein modifications. Antioxid Redox Signal 8: 173-184, 2006.

38. Artal-Sanz M and Tavernarakis N: Proteolytic mechanisms in necrotic cell death and neurodegeneration. FEBS Lett 579: 3287-3296, 2005.

39. Kim CH, Han SI, Lee SY, Youk HS, Moon JY, Duong HQ Park MJ, Joo YM, Park HG, Kim YJ, Yoo MA, Lim SC and Kang HS: Protein kinase C-ERK1/2 signal pathway switches glucose depletion-induced necrosis to apoptosis by regulating superoxide dismutases and suppressing reactive oxygen species production in A549 lung cancer cells. J Cell Physiol 211: 371-385, 2007 